\title{
Evaluation of Mechanical Properties of Sisal and Bamboo Fibres Reinforced with Polymer Matrix Composites Prepared by Compression Moulding Process
}

\author{
S. Krishna Mohan, ${ }^{1}$ Arul Thayammal Ganesan, ${ }^{2}$ M. Ramarao, ${ }^{3}$ Amol L. Mangrulkar, \\ S. Rajesh, ${ }^{5}$ Sami Al Obaid, ${ }^{6}$ Saleh Alfarraj, ${ }^{7}$ S. Sivakumar, ${ }^{8}$ and Manikandan Ganesan $\left(\mathbb{1}^{9}\right.$ \\ ${ }^{1}$ Department of Mechanical Engineering, E.G.S. Pillay Engineering College, Nagapattinam 611002, Tamilnadu, India \\ ${ }^{2}$ Department of Mechanical Engineering, St. Mary's Engineering College (SMEC), Hyderabad 686575, India \\ ${ }^{3}$ Department of Mechanical Engineering, Bharath Institute of Higher Education and Research, Chennai 6000073, \\ Tamilnadu, India \\ ${ }^{4}$ Department of Mechanical Engineering, Rajiv Gandhi Institute of Technology, Mumbai 400053, India \\ ${ }^{5}$ Department of Mechanical Engineering, Meenakshi College of Engineering, Chennai 6000078, Tamilnadu, India \\ ${ }^{6}$ Department of Botany and Microbiology, College of Science, King Saud University, P.O. Box 2455, Riyadh 11451, Saudi Arabia \\ ${ }^{7}$ Zoology Department, College of Science, King Saud University, Riyadh 11451, Saudi Arabia \\ ${ }^{8}$ Department of Bioenvironmental Energy, College of Natural Resources \& Life Science, Pusan National University, \\ Miryang-si-50463, Republic of Korea \\ ${ }^{9}$ Department of Electro-Mechanical Engineering, Faculty of Manufacturing, Institute of Technology, \\ Hawassa University, Ethiopia
}

Correspondence should be addressed to Manikandan Ganesan; mani301090@hu.edu.et

Received 9 September 2021; Accepted 26 October 2021; Published 29 November 2021

Academic Editor: P Ganeshan

Copyright (c) 2021 S. Krishna Mohan et al. This is an open access article distributed under the Creative Commons Attribution License, which permits unrestricted use, distribution, and reproduction in any medium, provided the original work is properly cited.

\begin{abstract}
Today's modern, dynamic world would be impossible to imagine without the concept of composite material advancement. Various studies are being conducted in this area in order to reach the desired level. In terms of compatibility, natural fibre reinforced polymer-based composites and synthetic fibre composites are very similar. Because they are lightweight, nontoxic, and nonabrasive, they are very popular with consumers. They are also readily available and affordable. Composite materials made from natural fibre have superior mechanical properties compared to those made from synthetic fibre. As part of this research, an epoxybased composite with bamboo and sisal fibre reinforcement is examined. Reinforced with epoxy resin, bamboo fibre and sisal fibre are used to make composite materials. The effect of adding bamboo fibre and sisal fibre in various weight percentages on the mechanical behaviour of composites is investigated.
\end{abstract}

\section{Introduction}

Natural fibres are superior to artificial fibres because they are lighter, denser, and more environmentally friendly and have a higher specific strength. On the downside, they have a low gloss finish and are more prone to absorbing moisture [1]. There are also some quality variations. Automobile, packaging, aerospace, construction, and other industries commonly use natural fibre composites. So long as the fibre content does not reach an optimal level, the composites' tensile strength increases [2]. On account of environmental pollution and energy shortages, scientists and researchers began paying close attention to biomass composites in the early 21 st century [3-7]. Plant fibres such as sisal, bamboo, bananas, and kenaf have been effectively employing them for reinforcement in addition to thermoplastic and thermoset matrixes. Natural fibres have a number of well-known advantages over synthetic fibres $[8,9]$. Additionally, they have 
high strength and elasticity modulus, as well as low price and low density. For example, sisal plant fibres have lower ultimate tensile strength than bamboo [10]. More than 500 bamboo species grow in China, which has a bamboo forest covering around 67,000 hectares, accounting for about onefourth of the world's bamboo forests [11]. Bamboo is produced in China, which is the world's most famous bambooproducing country. But only about $40 \%$ of the natural bamboo resources are currently being used [12]. Its low density, stiffness, and strength as well as its rapid growth have made bamboo popular $[13,14]$. Scortechinii is abundant and has excellent mechanical properties. As a general rule, 3-5-year-old bamboo should be used in the construction industry [15]. Prior to the fibre's extraction, several treatments must be performed on the bamboo culms. Bamboo fibre extraction methods include retting, steam explosion, alkali treatment, degumming, grinding, and crushing [16-19]. The mechanical properties of a composite are improved when the fibres and matrices are well bonded at the interface. When the matrix becomes loaded, it will be transferred to the fibres [20]. According to some researchers, composites' mechanical properties are improved by interfacial strength $[21,22]$. As a result of its versatility, bamboo is used in a variety of composite materials. Forms include short bamboo fibres, long bamboo strips, and the whole volume of bamboo. A growing number of researchers are interested in developing stronger bamboo fibre for use in industrial products [23]. Using vacuum-assisted resin transfer moulding, bamboo fibres and vinyl ester resins were combined to create environmentally friendly fibre reinforced composites. Using steam explosion, alkali extraction, and chemical extraction, bamboo fibre bundles were extracted prior to fabrication of green composites [24]. According to a comparison of the two materials, jute fibre reinforced epoxy composites had higher Young's modulus values than bamboo fibre reinforced epoxy composites [25]. Polymer composites may benefit from the addition of sisal fibre as a reinforcement. Sisal fibre has potential uses in the aircraft and automobile industries beyond traditional ones (such as ropes, carpets, and mats). Many factors influence how sisal fibre behaves physically and mechanically. These include the fibre's source, age, and location. By altering the surface of the hydrophilic sisal fibre, the hydrophobic polymer matrix has better interfacial adhesion with the hydrophilic fibre [26-28]. Bamboo fibre reinforced epoxy composites showed good longitudinal flexural strength. A number of studies have found that natural fibres such as jute and bamboo can affect the mechanical and physical strength of composites [29-31]. In order to replace conventional materials with natural fibre composites, hybrid combinations of natural fibres are preferred [32]. Because of its excellent mechanical properties, chemical resistance, and electrical insulation characteristics, polymer epoxy resin is used in the majority of bamboo fibre composite studies. The effects of various fibre volume fractions and fracture pattern morphology on bamboo fibre composites at room and elevated temperatures are described in detail. For the purpose of this study, we used varying amounts of bamboo and sisal fibres with epoxy resin to create hybrid composite specimens. Pure and hybrid composite specimens underwent tensile, flexural, compression, and impact tests to determine mechanical properties. Bamboo and sisal fibres were mixed with epoxy matrix to determine how much of each should be added to achieve desired strength of fibre in composites [7, 14, 33-36]. Bamboo and sisal fibre composites with different volume fractions were also evaluated for their mechanical properties.

\section{Experimental Plans}

\subsection{Materials}

2.1.1. Sisal Fibre and Its Extraction. A tropical or subtropical temperature is more conducive to sisal plant growth; it grows best above $30^{\circ} \mathrm{C}$. Each plant produces 160 swordshaped leaves over the course of its seven-year lifespan. Ropes, carpets, and so on are typically made from the 600-900 fibres found in the jute. They are removed when they reach an angle of greater than $40^{\circ}$ with respect to their upright position. The leaves are then repeatedly beaten with rollers with rounded knife edges, a process called decortication. Squeezing the pulp from the leaf releases the fibres. In order to remove dust and other unwanted contents from the fibres, they are then exposed to the Sun for 4 to 5 days.

2.1.2. Bamboo Fibre and Its Extraction. The pseudo-stem of the bamboo plant is used to extract the bamboo fibres. This plant can reach a height of 15 to 20 feet, depending on the region and the climate. In addition to being 4 to $6 \mathrm{~cm}$ wide and 2 to $3 \mathrm{~cm}$ thick, the stalk's length is determined by the plant's height. The stalk's outer sheath contains fibres. $80 \mathrm{~cm}$ is cut off the plant's qualified stem, and the outer sheath is removed from it. It is then removed by crushing sections of the pulpy material between two roller drums and scraping them around the circumference of each drum. As the name suggests, tuxies is the term used to describe a process of removing fibres from the stalk. A thorough washing and drying operation in the sunlight for a few days is required to remove any remaining moisture.

2.1.3. Epoxy. Epoxy resin is an epoxy oligomer. Once the hardener or curing agent has been introduced into the mix, it takes on a three-dimensional structure. Epoxy resin properties can be altered by using different epoxy oligomers and curing agents. As matrix material, epoxy-LY556 with HY951 hardener is used. The resin-to-hardener weight-to-weight ratio is $10: 1$.

2.1.4. Composite Fabrication. In this case, the composite laminates used in this work were made by compression moulding (Figure 1). Bamboo and sisal fibres that have been exposed to the Sun are first separated and chopped. Epoxy resin, bamboo, and sisal fibre were combined in five different compositions (BS1-90, 10, and 0), (BS2-90, 10, and 10), (BS4-80, 12.5, and 7.5). (BS5-80, 17.5, and 2.5). Bamboo, sisal, bamboo-sisal fibres, and epoxy resin were used to create the composites, with the appropriate 


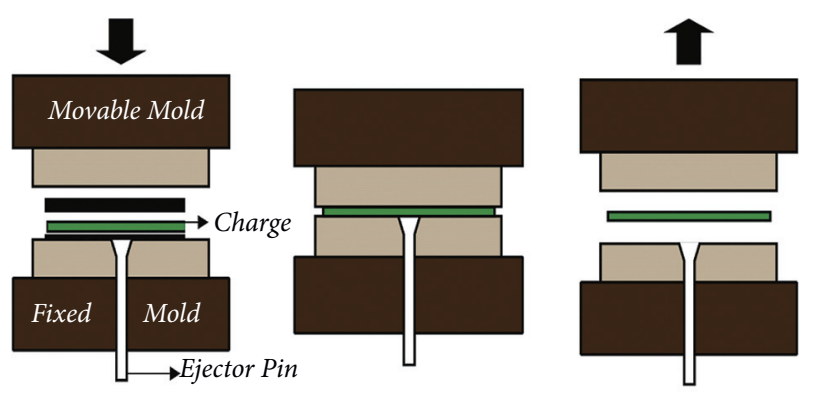

Final Molded Product

Figure 1: Schematic of compression moulding technique.

hardness selected. With a $250 \times 250 \times 20 \mathrm{~mm}$ mould, the present work was created.

Epoxies are more resistant to water and heat than other polymeric matrices and have high corrosion resistance $[37,38]$. In order to prevent resin from being deposited during the squeezing process, a polythene sheet was placed over the bottom jaw. Natural fibre premixed with epoxy resin was applied to the mould after the epoxy resin had been applied. Using a 150-ton hydraulic compression machine, the well-mixed compositions were compressed, and then the resin was applied to the top. For uniform resin distribution throughout the compositions, the pressure was gradually increased to remove trapped air. It took nearly 18 hours to cure the laminate under constant pressure. It was the same with other composite laminates. Table 1 shows the weight and volume percentages of bamboo fibre, sisal fibre, epoxy resin mixture, and laminate. In order to smooth the edges, burs were cut with a saw and rough edges were removed with emery sheets after the compressed laminate had been removed from the compression moulding machine. Most of the thermoset and thermoplastic polymer composites extensively use the compression moulding process. It is widely used in the high-volume production of composite components, like structural and automobile parts.

\subsection{Specimen Preparation for Mechanical Test}

2.2.1. Tensile Test. Tensile strength refers to a material's ability to stretch without snapping. ASTM D3039 was used to determine the laminate's tensile strength. The specimen needs to be checked to make sure that breaks occur where they should, and their necessity depends on where they occur. The specimen's ends were clamped in between the jaws of the clamp. In other words, the specimen is pulled taut by the jaw movement. This force was measured as a function of gauge length change. The test was performed on a Naveen Engineering universal testing machine with a maximum load capacity of $400 \mathrm{kN}$. Four millimetres per minute was used to load the samples. There were five samples per laminate for each of the three composite specimen types that were tensile tested. Figure 2 shows the tensile testing machine.
2.2.2. Flexural Test. During flexural testing, the specimen is subjected to tensile and compressive stresses, resulting in a shear stress along the specimen's centerline. The beam could only be bent by applying force. On the universal testing machine, with a load capacity of $400 \mathrm{kN}$, a flexural test was conducted. The ASTM D790 standard was used to measure the nominal specimen. Because of this, specimens were placed in the middle of two supports, 75 millimetres apart. $4 \mathrm{~mm} / \mathrm{min}$ of load was applied to the specimen until it fractured and broke. According to Figure 3, this test involves flexural testing of a specimen. The flexural stress was calculated using the maximum load at failure.

2.2.3. Compression Test. Compressive strength refers to a material's ability to withstand a load without lateral deformation. In order to determine the laminate's tensile strength, ASTM D3410 was used. The specimen needs to be checked to make sure that breaks occur where they should, and their necessity depends on where they occur. The specimen's ends were clamped in between the jaws of the clamp. The specimen is compressed as the jaw moves. This force was measured as a function of gauge length change. A compression test was carried out on a Naveen Engineering universal testing machine with a maximum load capacity of $400 \mathrm{kN}$. The samples were loaded at a rate of 4 millimetres per minute. In order to obtain an average value, five samples from each of the five types of composite specimens were subjected to compression specimen.

2.2.4. Impact Test. Figure 4 shows the impact testing machine. This is the material's ability to withstand sudden application of load. Using the Izod impact test rig, we evaluated the laminates' impact resistance and abrasion resistance. This test method measured the kinetic energy required to initiate a fracture and continue it until the specimen breaks. ASTM D4812 is the standard measurement for the Izod test. An air pendulum blew kinetic energy onto a test specimen standing upright. Grippers were used to hold the test specimen vertically. During the toughness and ductility tests, a scale was used to measure how much energy was absorbed by the material before it broke apart. The specimen description for the Izod impact test is shown in Figure 5.

\section{Results and Discussion}

3.1. Tensile Strength. Nine different types of laminates are tested in the UTM to determine their tensile strength capabilities. Figure 6 shows the tensile strength of five composite specimens. Sisal is added to bamboo fibre to increase its tensile strength. Composite specimens with higher sisal fibre content in the skin layers stretch more at break than specimens made of bamboo fibre. Figure 6 shows that the tensile strength of the composite is directly related to the amount of bamboo and sisal fibre in it. The specimen fractures at $80 \mathrm{wt}$. percent epoxy resin, $17.5 \mathrm{wt}$. percent bamboo fibre, and $2.5 \mathrm{wt}$. percent sisal fibre reinforced composites. On the graph, the stress-strain values that 
TABLE 1: Weight percentages of matrix and reinforcement materials.

\begin{tabular}{lccc}
\hline Specimen description & Matrix material (epoxy resin) & Primary reinforcement (bamboo fibre) & Secondary reinforcement (sisal fibre) \\
\hline B10/S0 & 90 & 10 & 0 \\
B0/S10 & 90 & 0 & 10 \\
B10/S10 & 80 & 10 & 10 \\
B12.5/S7.5 & 80 & 12.5 & 7.5 \\
B17.5/S2.5 & 80 & 17.5 & 2.5 \\
\hline
\end{tabular}

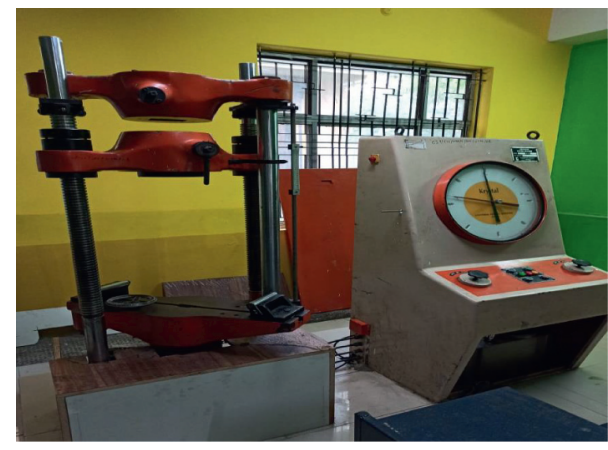

Figure 2: Tensile test machine.

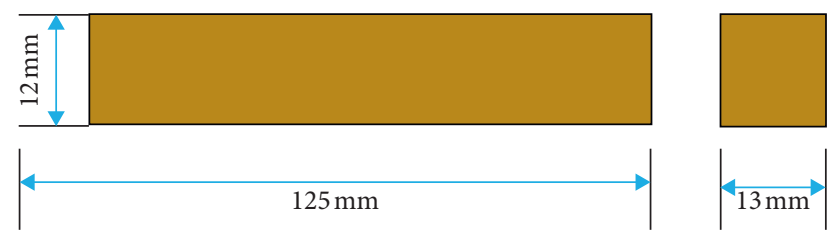

Figure 3: Specimen description for flexural test (ASTM D790 standard).

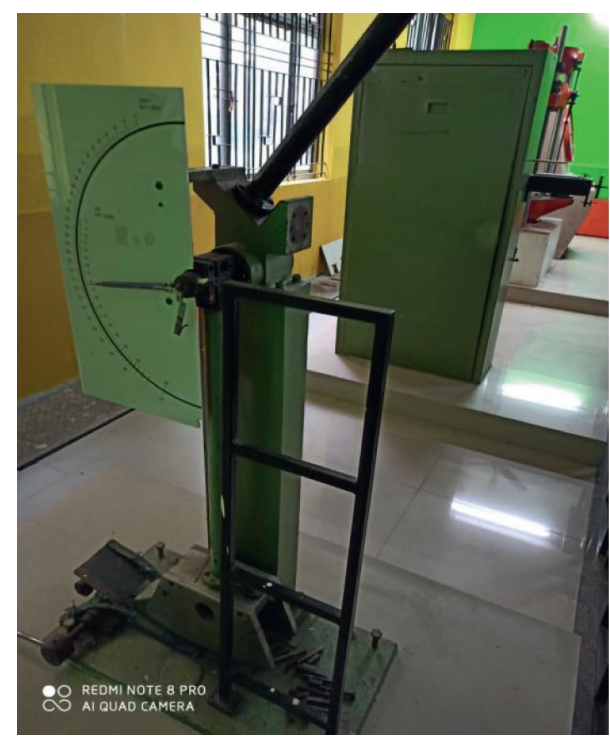

Figure 4: Impact test machine.

correspond to the tensile modulus of laminates can be measured. For all composite specimens, typical stress-strain curves were generated using the UTM. At its yield strength, the specimen begins to behave like brittle material and eventually breaks. UTM also provided a comparison plot of

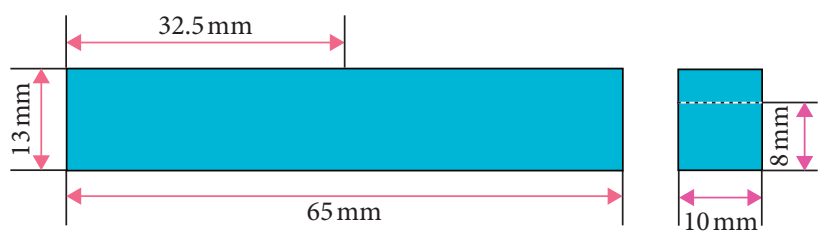

FIGURE 5: Specimen description for Izod impact test (ASTM D4812 standard).

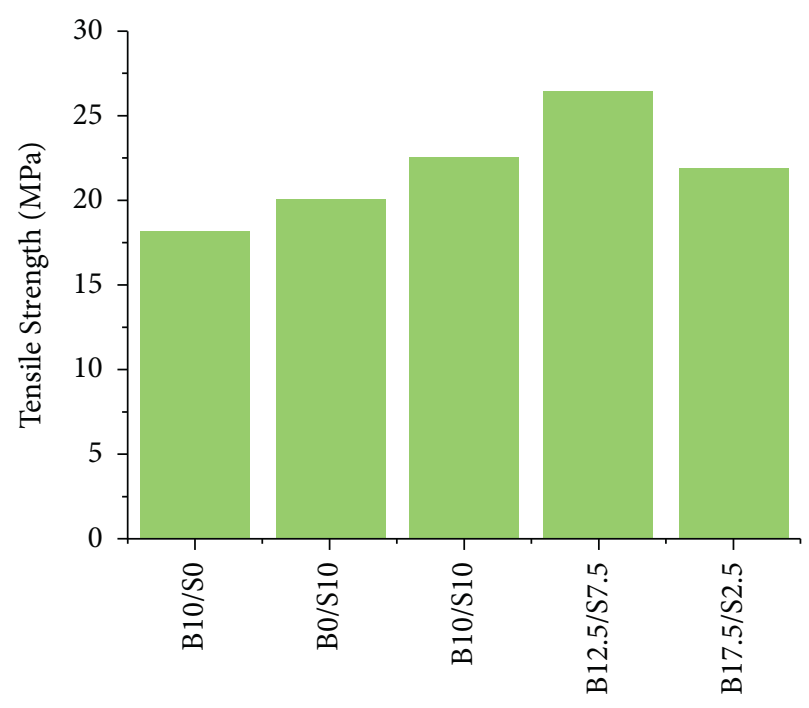

Composite Specimens

Figure 6: Tensile strength of the composite specimens.

load and displacement curves for each laminate during the tension test process. B0/S10 laminates with 100\% sisal fibre have tensile strengths of 18.07 and $20.03 \mathrm{MPa}$, respectively, while B10/S10 composites with randomly mixed bamboo/ sisal fibre have tensile strengths of 22.64, 26.41, and 21.82 $\mathrm{MPa}$, respectively. Tensile properties of laminates are improved by $32 \%$ and $24 \%$ when bamboo fibre and sisal fibre are mixed together in higher weight percentages of bamboo fibre than sisal fibre. Naturally hybrid composite tensile strength increases with bamboo content. The tensile strength of bamboo fibre is increased by 32,24 , and $14 \%$, respectively, by adding sisal fibre. There is no doubt that adding sisal fibre to bamboo fibre reinforced composite materials improves their strength, and that mixing bamboo fibre with sisal at higher weight ratios increases their resistance to tensile forces. Pure bamboo or sisal fibres cannot match the tensile strength of a hybrid bamboo-sisal fibre reinforced with 
epoxy resin. It is also possible to compare maximum displacement and length of the various combination sets.

3.2. Flexural Strength. Figure 7 shows the flexural strength measured using the UTM. A sandwich material of bamboo and sisal fibre is found to be stronger than the other combinations. The load is evenly distributed between fibres and matrix in laminates that have been subjected to gradual loading before rupture. Cracks form and propagate along the laminate cross section due to poor adhesion between the fibre and matrix. $46.81 \mathrm{MPa}$ is the higher flexural strength of the composites, attained at the combination of (B12.5/S7.5). There are almost no differences in strength between the bamboo and sisal fibre composite materials. It was found that the flexural strength increased by $13.45,8.28$, and $4.53 \%$ when sisal fibres were added to the bamboo fibre laminate and epoxy resin matrix, but it decreased by $3.54 \%$ when excess sisal fibre content was added. There is a maximum flexural strength of $46.81 \mathrm{MPa}$ in composite specimens reinforced with $12.5 \mathrm{wt}$. percent of bamboo fibre and $7.5 \mathrm{wt}$. percent of sisal fibres (B12.5/S7.5). As shown in Figure 7, all composite specimens have similar flexural strengths. The hybrid bamboo-sisal fibre reinforced composite specimen outperforms the pure bamboo and sisal fibre reinforced composite specimens, and the properties seem to improve with the limited addition of sisal fibres, while the addition beyond a certain limit affects its strength-absorbing characteristics. With the 17.5 weight percent bamboo fibre and 2.5 weight percent sisal groupings, flexural properties improved less than with the 12.5 weight percent bamboo fibre and 7.5 weight percent sisal groupings, relative to each other. The distribution of reinforcement loads (compression and tension loads) and shearing forces in intermediate layers becomes less uniform as the number of layers increases.

3.2.1. Compressive Strength. Compressive strength was measured using the UTM as shown in Figure 8. It has been found that sandwich materials made from bamboo and sisal fibre are stronger than other combinations of these two materials. In laminates that have been subjected to gradual loading before rupture, the load is evenly distributed between fibres and matrix. Laminated cross sections crack due to poor adhesion between fibre and matrix. 26.92 MPa is the higher compression strength of the composites, attained at the combination of (B17.5/S2.5). There are almost no differences in strength between the bamboo and sisal fibre composite materials. However, the flexural strength is increased by $19.58,11.52,8.21$, and $3.831 \%$ when sisal fibres are added in excess to the bamboo fibre laminate and epoxy resin matrix. There is a maximum flexural strength of 26.92 MPa observed in composite specimens reinforced with 17.5 wt. percent bamboo fibre and 2.5 wt. percent sisal fibre (B17.5/S2.5). A comparison of all composite specimens' compressive strength is depicted in Figure 8. In addition, the properties of the bamboo-sisal fibre reinforced hybrid composite specimen seem to improve with the addition of more sisal fibres, while adding more fibres beyond a certain point also improves its strength-absorbing characteristics.

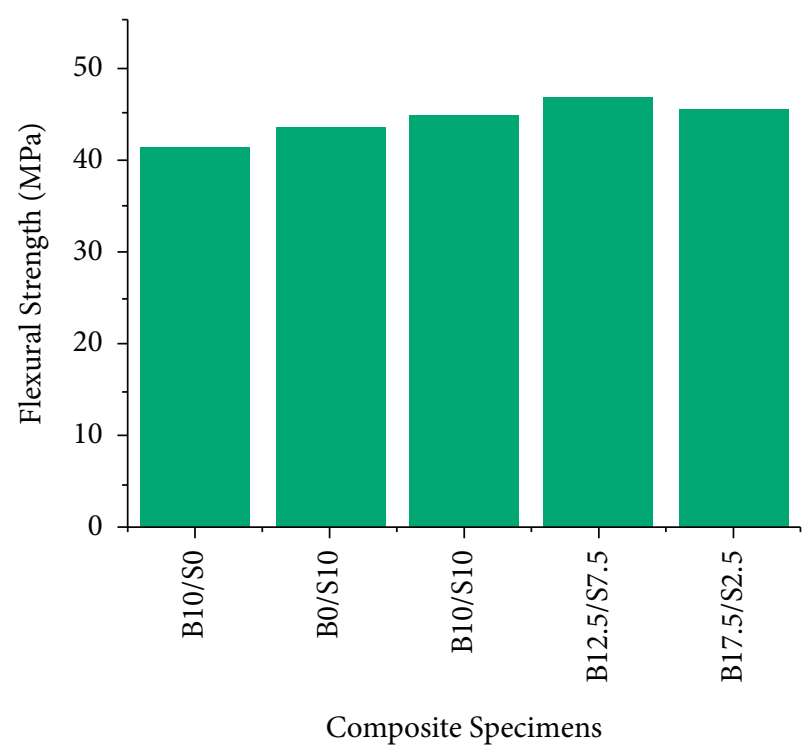

Figure 7: Flexural strength of the composite specimens.

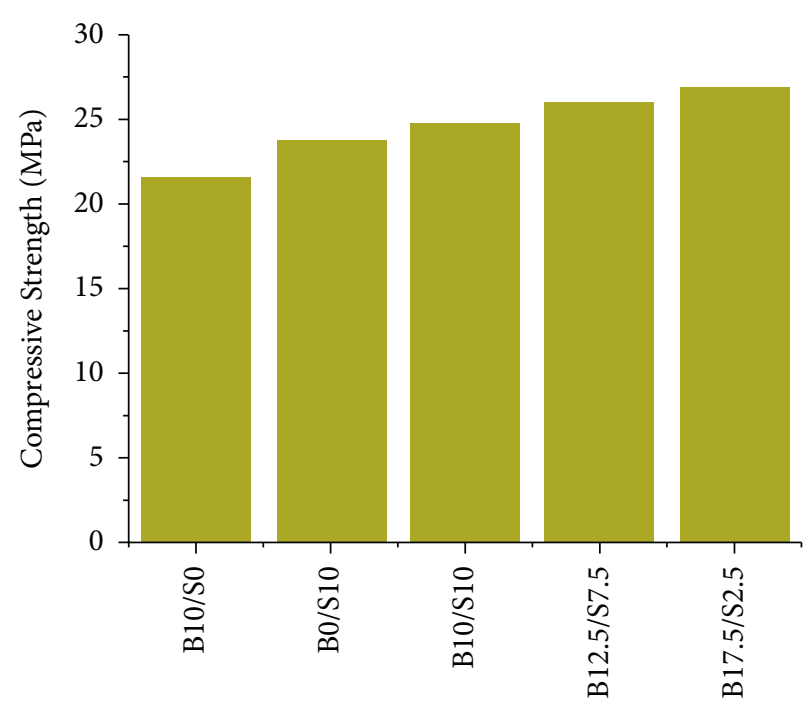

Composite Specimens

FIGURE 8: Compressive strength of the composite specimens.

17.5 wt. percent bamboo fibre groupings and $2.5 \mathrm{wt}$. percent sisal groupings show the greatest improvement in compressive properties, while $12.5 \mathrm{wt}$. percent bamboo fibre and $7.5 \mathrm{wt}$. percent sisal groupings show the least improvement. The distribution of reinforcement loads (compression and tension loads) and shearing forces in intermediate layers becomes less uniform as the number of layers increases.

3.2.2. Impact Energy. Five different compositions are tested for impact resistance. The Izod impact test machine is used to determine the energy lost during the impact process. Energy absorption by a specimen after it has been struck by an extremely heavy blow is shown in Figure 9. Hybrid fibre 


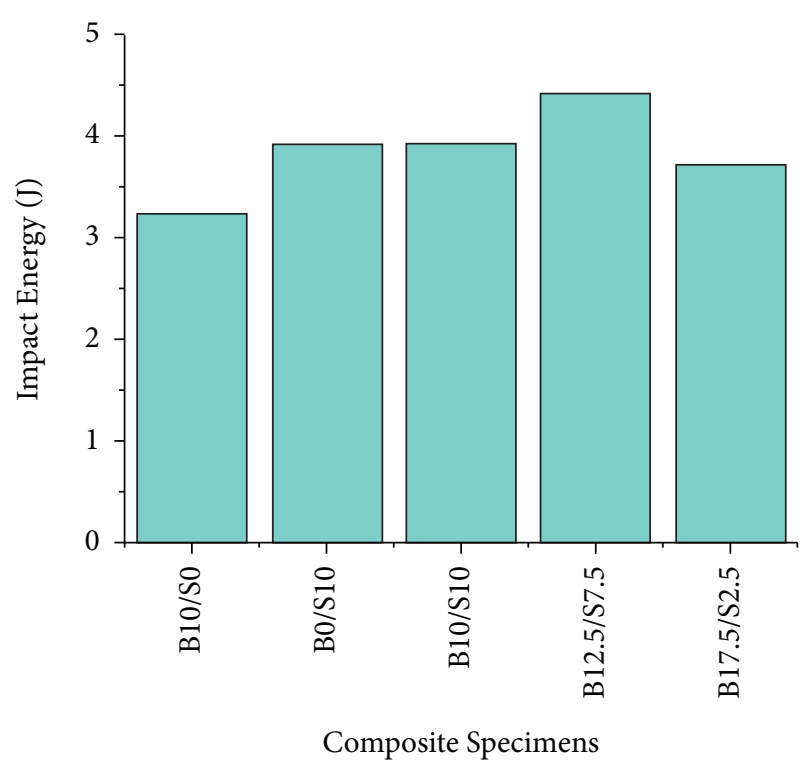

FIGURE 9: Impact energy of the composite specimens.

combinations with a higher proportion of bamboo fibre and a smaller proportion of sisal fibre outperform natural fibres. The crack propagates as a result of a loss of adhesion between the specimen's fibres and matrix. While the pure bamboo and sisal fibre reinforced composite specimen have impact energies of around 3.2 J and 3.9 J, the epoxy resin matrix with $12.5 \mathrm{wt}$. percent bamboo fibres and $7.5 \mathrm{wt}$. percent sisal fibres has an impact energy of $4.4 \mathrm{~J}$. Researchers found that natural fibre laminates had lower impact energy than a bamboo-sisal hybrid composite, according to a study published in Nature Materials. Both the pure bamboo and sisal fibre composite specimens have a nearly identical impact energy as a result. Impact properties of bamboo fibre mat are dramatically improved when sisal fibres are added. Specimens made from composite materials with B10 and S10 content have impact performance improvements of $13 \%$ and $31 \%$, respectively. B12.5/S7.5 composite specimen samples have the highest impact energy, which is $31 \%$ and $13 \%$ higher than pure bamboo and sisal fibre reinforced composite specimens, respectively. The glass fibres in hybrid composites absorb a large amount of energy because bamboo and sisal fibres alternate between layers. There is no positive trend in the impact performance of bamboo and sisal fibres when they are combined in equal weight ratios. As the load travels transversely, the impact properties of natural fibre layers become less effective. As shown in Figure 9, different composite specimens can be compared in terms of impact energy absorption.

\section{Conclusions}

The mechanical behaviour of bamboo fibre reinforced epoxy-based polymer composite was studied. This experimental investigation produced the following results.

(i) Bamboo and sisal fibre reinforced epoxy composite materials have been successfully fabricated. (ii) Bamboo and sisal fibres have a significant influence on composite mechanical properties, including tensile strength, flexural strength, compressive strength, and impact energy.

(iii) A lack of proper bonding at the interface of bamboo and sisal fibres causes mechanical properties to degrade with the exception of compressive behaviour. Load transfer to bonding fibres is disrupted as a result. Bamboo and sisal fibres with higher compositions may have lower tensile strength, impact strength, and flexural strength because of this phenomenon.

(iv) The tensile strength of bamboo fibre is increased by 32,24 , and $14 \%$, respectively, by adding sisal fibre. Composite specimens reinforced with 12.5 wt. percent bamboo fibre and 7.5 wt. percent sisal fibres had a maximum flexural strength of $46.81 \mathrm{MPa}$.

(v) In composite materials, bamboo (12.5 weight percent) and sisal fibre (7.5 weight percent) are added in order to increase tensile strength, flexibility, and impact resistance.

\section{Data Availability}

The data used to support the findings of this study are included within the article. Further data or information is available from the corresponding author upon request.

\section{Conflicts of Interest}

The authors declare that there are no conflicts of interest regarding the publication of this article.

\section{Acknowledgments}

The authors appreciate the support from Hawassa University, Ethiopia. The authors also thank Bharath Institute of Higher Education and Research, Chennai, and this project was supported by Researchers Supporting Project number (RSP-2021/315) King Saud University, Riyadh, Saudi Arabia.

\section{References}

[1] H. Ku, H. Wang, N. Pattarachaiyakoop, and M. Trada, “A review on the tensile properties of natural fiber reinforced polymer composites," Composites Part B: Engineering, vol. 42, no. 4 , pp. 856-873, 2011.

[2] O. Faruk, A. K. Bledzki, H.-P. Fink, and M. Sain, "Progress report on natural fiber reinforced composites," Macromolecular Materials and Engineering, vol. 299, no. 1, pp. 9-26, 2014.

[3] R. Jeencham, N. Suppakarn, and K. Jarukumjorn, "Effect of flame retardants on flame retardant, mechanical, and thermal properties of sisal fiber/polypropylene composites," Composites Part B: Engineering, vol. 56, pp. 249-253, 2014.

[4] V. Mohanavel, T. Raja, A. Yadav, M. Ravichandran, and J. Winczek, "Evaluation of mechanical and thermal properties of jute and ramie reinforced epoxy-based hybrid composites," Journal of Natural Fibers, vol. 2021, Article ID 1958432, 11 pages, 2021. 
[5] A. Alavudeen, N. Rajini, S. Karthikeyan, M. Thiruchitrambalam, and N. Venkateshwaren, "Mechanical properties of banana/ kenaf fiber-reinforced hybrid polyester composites: effect of woven fabric and random orientation," Materials \& Design, vol. 66, pp. 246-257, 2015.

[6] M. J. M. Ridzuan, M. S. A. Majid, M. Afendi, M. N. Mazlee, and A. G. Gibson, "Thermal behaviour and dynamic mechanical analysis of Pennisetum purpureum/glass-reinforced epoxy hybrid composites," Composite Structures, vol. 152, pp. 850-859, 2016.

[7] A. C. Manalo, E. Wani, N. A. Zukarnain, W. Karunasena, and K.-t. Lau, "Effects of alkali treatment and elevated temperature on the mechanical properties of bamboo fibre-polyester composites," Composites Part B: Engineering, vol. 80, pp. 73-83, 2015.

[8] X. Li, L. G. Tabil, and S. Panigrahi, "Chemical treatments of natural fiber for use in natural fiber-reinforced composites: a review," Journal of Polymers and the Environment, vol. 15, no. 1, pp. 25-33, 2007.

[9] S. V. Joshi, L. T. Drzal, A. K. Mohanty, and S. Arora, "Are natural fiber composites environmentally superior to glass fiber reinforced composites?" Composites Part A: Applied Science and Manufacturing, vol. 35, no. 3, pp. 371-376, 2004.

[10] A. V. R. Prasad and K. M. Rao, "Mechanical properties of natural fibre reinforced polyester composites: jowar, sisal and bamboo," Materials \& Design, vol. 32, no. 8-9, pp. 4658-4663, 2011.

[11] X. Chen, X. Zhang, Y. Zhang, T. Booth, and X. He, "Changes of carbon stocks in bamboo stands in China during 100 years," Forest Ecology and Management, vol. 258, no. 7, pp. 1489-1496, 2009.

[12] J.-H. Chen, J.-K. Xu, P.-L. Huang, and R.-C. Sun, "Effect of alkaline pretreatment on the preparation of regenerated lignocellulose fibers from bamboo stem," Cellulose, vol. 23, no. 4, pp. 2727-2739, 2016.

[13] K. Okubo, T. Fujii, and E. T. Thostenson, "Multi-scale hybrid biocomposite: processing and mechanical characterization of bamboo fiber reinforced PLA with microfibrillated cellulose," Composites Part A: Applied Science and Manufacturing, vol. 40, no. 4, pp. 469-475, 2009.

[14] L. Osorio, E. Trujillo, A. W. Van Vuure, and I. Verpoest, "Morphological aspects and mechanical properties of single bamboo fibers and flexural characterization of bamboo/epoxy composites," Journal of Reinforced Plastics and Composites, vol. 30, no. 5, pp. 396-408, 2011.

[15] D. Ren, Z. Yu, X. Zhang, H. Wang, H. Wang, and Y. Yu, "Quantitative characterization of the interface between bamboo fiber and polypropylene with pull-out test and nanomechanical imaging," Journal of Materials Science, vol. 52, no. 3, pp. 1296-1307, 2017.

[16] P. Zakikhani, R. Zahari, M. T. H. Sultan, and D. L. Majid, "Extraction and preparation of bamboo fibre-reinforced composites," Materials \& Design, vol. 63, pp. 820-828, 2014.

[17] K. M. M. Rao and K. M. Rao, "Extraction and tensile properties of natural fibers: vakka, date and bamboo," Composite Structures, vol. 77, no. 3, pp. 288-295, 2007.

[18] K. Okubo, T. Fujii, and Y. Yamamoto, "Development of bamboo-based polymer composites and their mechanical properties," Composites Part A: Applied Science and Manufacturing, vol. 35, no. 3, pp. 377-383, 2004.

[19] S. Biswas, Q. Ahsan, A. Cenna, M. Hasan, and A. Hassan, "Physical and mechanical properties of jute, bamboo and coir natural fiber," Fibers and Polymers, vol. 14, no. 10, pp. 1762-1767, 2013.
[20] B. Wang, S. Panigrahi, L. Tabil, and W. Crerar, "Pre-treatment of flax fibers for use in rotationally molded biocomposites," Journal of Reinforced Plastics and Composites, vol. 26, no. 5, pp. 447-463, 2007.

[21] E. S. Rodriguez, P. M. Stefani, and A. Vazquez, "Effects of fibers' alkali treatment on the resin transfer molding processing and mechanical properties of jute-vinylester composites," Journal of Composite Materials, vol. 41, no. 14, pp. 1729-1741, 2007.

[22] H.-S. Yang, H.-J. Kim, J. Son, H.-J. Park, B.-J. Lee, and T.-S. Hwang, "Rice-husk flour filled polypropylene composites; mechanical and morphological study," Composite Structures, vol. 63, no. 3-4, pp. 305-312, 2004.

[23] H.-S. Yang, H.-J. Kim, H.-J. Park, B.-J. Lee, and T.-S. Hwang, "Effect of compatibilizing agents on rice-husk flour reinforced polypropylene composites," Composite Structures, vol. 77, no. 1, pp. 45-55, 2007.

[24] H. Kim, K. Okubo, T. Fujii, and K. Takemura, "Influence of fiber extraction and surface modification on mechanical properties of green composites with bamboo fiber," Journal of Adhesion Science and Technology, vol. 27, no. 12, pp. 13481358, 2013.

[25] S. Biswas, S. Shahinur, M. Hasan, and Q. Ahsan, "Physical, mechanical and thermal properties of jute and bamboo fiber reinforced unidirectional epoxy composites," Procedia Engineering, vol. 105, pp. 933-939, 2015.

[26] R. V. Silva, D. Spinelli, W. W. Bose Filho, S. Claro Neto, G. O. Chierice, and J. R. Tarpani, "Fracture toughness of natural fibers/castor oil polyurethane composites," Composites Science and Technology, vol. 66, no. 10, pp. 1328-1335, 2006.

[27] S. Biswas, K. Debnath, and A. Patnaik, "Mechanical behaviour of short bamboo fiber reinforced epoxy composites filled with alumina particulate," 2012.

[28] L. A. Pothan, C. N. George, M. Jacob, and S. Thomas, "Effect of chemical modification on the mechanical and electrical properties of banana fiber polyester composites," Journal of Composite Materials, vol. 41, no. 19, pp. 2371-2386, 2007.

[29] K. Joseph, S. Thomas, and C. Pavithran, "Dynamic mechanical properties of short sisal fiber reinforced low density polyethylene composites," Journal of Reinforced Plastics and Composites, vol. 12, no. 2, pp. 139-155, 1993.

[30] T. W. Frederick and W. Norman, "Natural fibers plastics and composites," EUA Kluwer Acad. Publ, vol. 2, no. 3, 2004.

[31] X. Y. Liu and G. C. Dai, "Surface modification and micromechanical properties of jute fiber mat reinforced polypropylene composites," Express Polymer Letters, vol. 1, no. 5, pp. 299-307, 2007.

[32] M. Boopalan, M. Niranjanaa, and M. J. Umapathy, "Study on the mechanical properties and thermal properties of jute and banana fiber reinforced epoxy hybrid composites," Composites Part B: Engineering, vol. 51, pp. 54-57, 2013.

[33] J.-K. Huang and W.-B. Young, "The mechanical, hygral, and interfacial strength of continuous bamboo fiber reinforced epoxy composites," Composites Part B: Engineering, vol. 166, pp. 272-283, 2019.

[34] M. Yang, F. Wang, S. Zhou et al., "Thermal and mechanical performance of unidirectional composites from bamboo fibers with varying volume fractions," Polymer Composites, vol. 40, no. 10, pp. 3929-3937, 2019.

[35] S. S. Chee, M. Jawaid, M. T. H. Sultan, O. Y. Alothman, and L. C. Abdullah, "Thermomechanical and dynamic mechanical properties of bamboo/woven kenaf mat reinforced epoxy 
hybrid composites," Composites Part B: Engineering, vol. 163, pp. 165-174, 2019.

[36] F. Wang, M. Yang, S. Zhou, S. Ran, and J. Zhang, "Effect of fiber volume fraction on the thermal and mechanical behavior of polylactide-based composites incorporating bamboo fibers," Journal of Applied Polymer Science, vol. 135, no. 15, Article ID 46148, 2018.

[37] V. Mohanavel, S. Suresh Kumar, J. Vairamuthu, P. Ganeshan, and B. NagarajaGanesh, "Influence of stacking sequence and fiber content on the mechanical properties of natural and synthetic fibers reinforced penta-layered hybrid composites," Journal of Natural Fibers, vol. 2021, p. 13, Article ID 1875368, 2021.

[38] V. Fiore, G. Di Bella, and A. Valenza, "The effect of alkaline treatment on mechanical properties of kenaf fibers and their epoxy composites," Composites Part B: Engineering, vol. 68, pp. 14-21, 2015. 